\title{
Corrigendum to: Common genetic variation and performance on standardized cognitive tests
}

Elizabeth T Cirulli, Dalia Kasperavičiūtė, Deborah K Attix, Anna C Need, Dongliang Ge, Greg Gibson and David B Goldstein

European Journal of Human Genetics (2010) 18, 820; doi:10.1038/ejhg.2010.44

Correction to: European Journal of Human Genetics advance online publication, 3 February 2010; doi:10.1038/ejhg.2010.2

Since the publication of the above paper, the authors noticed that the acknowledgements section should include the following:
We acknowledge the Ellison Medical Foundation for partial funding of this study.

The authors would like to apologize for this mistake. 